\title{
Closed Fracture of Malar and Maxillary Bone
}

National Cancer Institute

\section{Source}

National Cancer Institute. Closed Fracture of Malar and Maxillary Bone. NCI Thesaurus.

Code C34489.

A traumatic break in the malar and maxillary bones that does not involve a break in the adjacent skin. 